\title{
Evaluating the performance of diagnostic methods for soil transmitted helminths in the Amhara National Regional State, Northwest Ethiopia
}

Abebe Fenta $^{1 *}$ (D), Tadesse Hailu², Megbaru Alemu², Endalkachew Nibret ${ }^{3}$, Arancha Amor ${ }^{4}$ and Abaineh Munshea ${ }^{3}$

\begin{abstract}
Background: Soil-transmitted helminths are more prevalent in tropics and sub-tropics including Ethiopia. Despite their high prevalence, direct saline microscopy with its low sensitivity has been used as a diagnostic method in almost all health facilities in Ethiopia. Alternative diagnostic methods which have higher sensitivity are not yet implemented. Therefore, this study aimed to compare and evaluate the performance of diagnostic methods for soil transmitted helminths.

Methods: A cross-sectional study among 520 school children was conducted from October to December, 2019 in Amhara National Regional State. The study participants were selected using systematic random sampling technique. Stool samples were processed via formol ether concentration, Kato-Katz, spontaneous tube sedimentation and agar plate culture techniques. Data was entered into Epi-data version 3.1 and analysis was done using SPSS version 20.0. The sensitivity, specificity, and negative predictive value were calculated against the combined result. Strength of agreement of the diagnostic methods was determined by Kappa value.

Results: The Overall prevalence of soil transmitted helminths was $40.8 \%$ using combination of methods. The prevalence $24.4,22.5$, and $32.4 \%$, respectively was recorded by using formol ether concentration, Kato-Katz and spontaneous tube sedimentation. The highest prevalence of hookworm (29.2\%) was detected by the agar plate culture. The sensitivity and negative predictive value of formol ether concentration were 57.9 and $78.4 \%$, for KatoKatz thick smear 55.2 and $76.4 \%$, for spontaneous tube sedimentation were 79.2 and $87.5 \%$ to soil transmitted helminths detection, respectively. The sensitivity and negative predictive value of agar plate culture to hookworm detection were 86.4 and $93.5 \%$, respectively.

Conclusion: Spontaneous tube sedimentation shows higher sensitivity in the detection of soil transmitted helminth infections. Agar plate culture method also indicated better performance for hookworm detection than other methods. Therefore, the employment of spontaneous tube sedimentation technique for routine laboratory and agar plate culture for research purposes will significantly aid in accurate diagnosis of parasitic infections.
\end{abstract}

Keywords: Soil-transmitted helminths, Diagnostic performance, Method comparison, School children, Ethiopia

\footnotetext{
*Correspondence: abebefenta19@gmail.com

${ }^{1}$ Health Science College, Debremarkos University, P.o.box: 269, Debre Markos, Ethiopia

Full list of author information is available at the end of the article
}

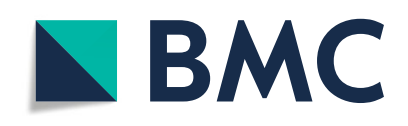

(- The Author(s). 2020 Open Access This article is licensed under a Creative Commons Attribution 4.0 International License, which permits use, sharing, adaptation, distribution and reproduction in any medium or format, as long as you give appropriate credit to the original author(s) and the source, provide a link to the Creative Commons licence, and indicate if changes were made. The images or other third party material in this article are included in the article's Creative Commons licence, unless indicated otherwise in a credit line to the material. If material is not included in the article's Creative Commons licence and your intended use is not permitted by statutory regulation or exceeds the permitted use, you will need to obtain permission directly from the copyright holder. To view a copy of this licence, visit http://creativecommons.org/licenses/by/4.0/. The Creative Commons Public Domain Dedication waiver (http://creativecommons.org/publicdomain/zero/1.0/) applies to the data made available in this article, unless otherwise stated in a credit line to the data. 


\section{Background}

The soil-transmitted helminths (STHs) that infect human include, Ascaris lumbricoides, Trichuris trichiura and hookworm species (Necator americanus and Ancylostoma duodenale) [1]. The global burden of disease due to STHs infections is estimated at 5.2 million disability-adjusted life years (DALYs) [2]. In Ethiopia, the number of people living in STHs endemic areas are estimated at 79 million $[3,4]$. The regional prevalence within the Amhara region was $36.4 \%$ for any STHs [5].

Transmission of STHs is through ingestion of eggs with food, water, soil and/or contaminated fingers or percutaneously by larvae depending on the species [6]. Once STHs enter the human system, they chronically infect children and result in chronic malnutrition and anaemia leading to physical and mental abnormality [7].

Several diagnostic techniques including; direct wet mount, Kato-Katz (KK), Spontaneous tube sedimentation (STS), Formol-ether concentration (FEC), agar plate culture (APC), immunodiagnostic and molecular techniques are employed however, they vary in their sensitivity, cost, simplicity and applicability [8,9]. The KK technique is mainly recommended to detect STHs infections [10, 11]. In effective diagnosis, detection methods must be accurate, simple and affordable for the whole population and provide results in a short period of time to effective prevention and control measures [12].

Low sensitive diagnostic methods like the wet mount technique leads to under diagnosis of STHs infections and may mislead physicians [13-16]. Proper detection of STHs using sensitive diagnostic methods is crucial in the national STHs prevention and control strategies. However, direct wet mount is still used as a routine diagnostic method for STHs infections in Ethiopia with its low sensitivity. This has a negative impact on the prevention and control plan. To push the STHs prevention and control strategies one step forward, updating and applying better sensitive, specific and cost effective diagnostic methods as a routine diagnostic approach is ideal in Ethiopia. This might reduce under diagnosis and under report of STHs infections in the country. Therefore, the aim of this study was to evaluate the performance of FEC, KK, STS and APC in STHs detection in Amhara National Regional State (ANRS).

\section{Method}

\section{Study design, period and area}

A cross-sectional study was conducted among primary school children from October to December, 2019 in ANRS. The ANRS consists of 10 zones and 157 districts and is divided into three major ecological zones: the highlands, midlands and the lowlands. The annual mean temperature is between $15^{\circ} \mathrm{C}$ and $21^{\circ} \mathrm{C}$. The mean annual rainfall is also $1165 \mathrm{~mm}$. According to the economic and finance office of the ANRS 2017 report, the total population of children (5-14 years) in the region is 5 , 996,074 [17].

Six districts and twelve primary schools (two primary schools in each district) were selected by simple random sampling technique and a systematic random sampling technique was used to select the study participants in each selected primary school as class roster was used as a sampling frame. The sample size was proportionally allocated for each school by taking the total number of students in each category into consideration.

Students who fall in the age range 6-14 years, gave consent and volunteered to participate were included whereas, students who took anti-helminthic drugs for the last 2 months prior to data collection or during data collection time were excluded from the study.

\section{Data collection and processing}

Approximately, $10 \mathrm{~g}$ of fresh stool sample was collected with $25.0 \mathrm{ml}$ stool cups from each study participant and transported to the nearby health institution within an hour. The fresh stool samples were processed with FEC, KK, STS and APC methods to detect STHs.

In the modified Richie's method, approximately $0.5 \mathrm{~g}$ fresh stool sample was added in the sample collecting tube containing $2.5 \mathrm{ml}$ of formalin and $1 \mathrm{ml}$ of ethyl acetate. The test tube was mixed well and centrifuged at 1500 revolutions for three minutes. Finally, the supernatant was discarded and the sediment was mixed and put on the microscope to detect the ova and the larva of STHS [18].

In the KK technique, a stool sample was pressed through a mesh screen to remove large particles. About $41.7 \mathrm{mg}$ of sieved stool was transferred to the templates which was put on a slide till the template whole is filled. Then, the template was removed and the stool sample was covered and pressed with cellophane which is previously immersed with Glycerol-malachite green. The KK thick smears were examined within $30 \mathrm{~min}$ for hookworm and after one hour up to $24 \mathrm{~h}$ for other intestinal parasites [11].

In the STS technique, approximately $3 \mathrm{~g}$ of fresh stool sample was weighed and homogenized in $10 \mathrm{ml}$ of normal saline solution. The mixture was filtered through surgical gauze into a $50 \mathrm{ml}$ plastic tube which was then filled with more saline solution to $50 \mathrm{ml}$ gauge, plugged, and shaken vigorously. The tube was left to stand for 45 min, and then discard the supernatant. A sample was taken from the bottom and put on a microscope slide and seen for ova and larva of STHs [9].

In APC technique, about $3 \mathrm{~g}$ of fresh stool was placed on the centre of a primary APC in a $100 \times 15 \mathrm{~mm}$ Petri dish. The Petri dish was sealed with adhesive tape and incubated at $26^{\circ} \mathrm{C}$ ) for two days. The surface of the agar- 
plate was analyzed daily with an inverted microscope for the presence of tracks of moving larvae. Then after, $5 \mathrm{ml}$ of a $10 \%$ formalin solution was added to the agar surface and waited for $5 \mathrm{~min}$. The excess formalin was collected with a conical test tube and centrifuged at 1500 for 5 min. Finally, the sediment was first seen for larvae of hookworm with microscope [19].

\section{Performance evaluation}

The detection rate and performance of FEC, STS, KK and APC methods to STHs was checked. The diagnostic agreements of methods were evaluated by Kappa value, number of observed agreements, number of agreements expected by chance and standard error of Kappa. Kappa result was interpreted as follows: values $\leq 0$ as indicating no agreement and $0.01-0.20$ as none to slight, $0.21-0.40$ as fair, $0.41-0.60$ as moderate, $0.61-0.80$ as substantial, and $0.81-1.00$ as almost perfect agreement [20].

\section{Data quality control}

Training was given for laboratory personnel about the study, data collection, and detection. The quality of reagents and instruments were checked. The stool samples were also checked for serial number, and quantity. To eliminate observer bias, each stool sample was examined immediately by two laboratory personnel. To maintain the reliability of the study findings, $15 \%$ of the results of each method were randomly selected and re-examined by a third laboratory personnel who was blind for the first stool examination. The principal investigator checked the discordant results and put the final result.

\section{Data analysis}

Data was entered in Epi-data version 3.1 and analyzed using SPSS version 20.0 statistical software for descriptive statistics. The sensitivity, specificity, negative predictive value and positive predictive values for each diagnostic method in STHs detection was calculated against the combined results as a "Gold" standard method. Kappa values were estimated at $95 \% \mathrm{CI}$ to determine the strength of agreement of the diagnostic methods. $P$-value $<0.05$ were considered as statistically significant.

\section{Ethical consideration}

Ethical clearance was obtained from College of Medicine and Health Science ethical review committee, Bahir Dar University and permission letter was obtained from ANR health bureau. Supporting letters were also obtained from ANR education bureau, Zonal and district education offices. Written informed consent was secured from parents/guardians of each study participant. Study participants infected with intestinal parasites were referred to doctors at the nearby health institution.

\section{Results}

\section{Socio-demographic characteristics of the study} participants

A total of five hundred twenty $(n=520)$ students were enrolled in this study. The mean age of study participants was 10.14 years ranged from 6 to 14 years with a standard deviation of 1.66 years. The male participants accounted for 266 (51.2\%). Four hundred ninety seven (95.6\%) participants were rural dwellers and 459 (88.3\%) of the participants were Orthodox in their religion.

\section{Prevalence of STHs}

From the total enrolled study subjects, the prevalence of parasites identified were $7.7,33.8,0.8,20.2,1.3,8.1,3.3$, 16.5 and $8.3 \%$ with the respective $A$. lumbricoides, hookworm, T. trichiura, S. mansoni, E. vermicularis, S. stercoralis, H. nana, E. histolytica/dispar and G. lamblia with a combined method. The overall prevalence of STHs was $40.8 \%$ with a combined method. The prevalence of hookworm, A. lumbricoides and T. trichiura infections by combined methods was $33.8,7.7$ and $0.8 \%$, respectively (Table 1). The detection rate $32.4,24.4$ and $22.5 \%$ to STHs infections was obtained using STS, FEC, and KK techniques, respectively. The prevalence of hookworm infection via the APC technique was $29.2 \%$ (Table 1 ).

Table 1 The prevalence of STHs using Combined, FEC, KK, STS and APC techniques among school children in ANRS, from October to December,2019. $(n=520)$

\begin{tabular}{|c|c|c|c|c|}
\hline \multirow[t]{2}{*}{ Parasite } & \multirow{2}{*}{$\begin{array}{l}\text { Diagnostic } \\
\text { technique }\end{array}$} & \multicolumn{3}{|c|}{ Prevalence detected by each method } \\
\hline & & $\mathrm{N}$ & $\%$ & $95 \% \mathrm{Cl}$ \\
\hline \multirow[t]{4}{*}{ A. lumbricoides } & Combined & 40 & 7.7 & $5.4-10$ \\
\hline & FEC & 13 & 2.5 & $1.2-3.8$ \\
\hline & KK & 20 & 3.8 & $2.2-5.5$ \\
\hline & STS & 32 & 6.2 & $4.2-8.4$ \\
\hline \multirow[t]{5}{*}{ Hookworm } & Combined & 176 & 33.8 & $29.8-37.9$ \\
\hline & FEC & 113 & 21.7 & $18.2-25.3$ \\
\hline & KK & 98 & 18.8 & $15.5-22.2$ \\
\hline & STS & 137 & 26.3 & $22.5-30.1$ \\
\hline & $A P C$ & 152 & 29.2 & $25.3-33.2$ \\
\hline \multirow[t]{4}{*}{ T. trichiura } & Combined & 4 & 0.8 & $0.02-1.5$ \\
\hline & FEC & 3 & 0.6 & $0.08-1.2$ \\
\hline & KK & 3 & 0.6 & $0.08-1.2$ \\
\hline & STS & 4 & 0.8 & $0.02-1.5$ \\
\hline \multirow[t]{4}{*}{ STHs } & Combined & 212 & 40.8 & $36.6-45.1$ \\
\hline & FEC & 127 & 24.4 & $20.1-28.3$ \\
\hline & KK & 117 & 22.5 & $19.1-26.3$ \\
\hline & STS & 168 & 32.4 & $28.4-36.5$ \\
\hline
\end{tabular}

$\mathrm{N}$ number positive, $\mathrm{Cl}$ Confidence interval 


\section{Detection and performance evaluation of diagnostic methods for STHs}

The detection rate of the combined methods to STHs was $1.81,1.67$, and 1.26 times more sensitive than $\mathrm{KK}$, FEC, and STS, respectively. The detection rate of the STS method to STHs was also 1.44 and 1.32 times more sensitive than KK and FEC methods, respectively (Table 2).

Better detection rate when two techniques used at a time was $35.8 \%$ by STS and KK, followed by $35.4 \%$ by STS and FEC, and $29.2 \%$ by KK and FEC in the identification of STHs infection. A combination of three methods (FEC, STS and KK) had higher detection rate (37.5\%) than combination of two methods (Table 3).

The STS method (79.2\%) had better sensitivity as compared to KK (55.2\%) and FEC (57.9\%) methods in STHs detection (Table 2). The sensitivity of KK technique for A. lumbricoides (50\%) infections was higher than FEC technique sensitivity for A. lumbricoides (32.5\%) infection (Table 2). The APC technique had better sensitivity (86.4\%) and NPV (93.5\%) in diagnosing hookworm infection compared to the STS (Sensitivity (77.8\%) and NPV (89.8\%)), FEC (Sensitivity (64.2\%) and NPV (84.5\%)) and KK (Sensitivity (55.7\%) and NPV (81.5\%)) techniques. However, all the four techniques had $100 \%$ specificity and positive predictive values in STHs detection (Table 2).

\section{Agreement of the diagnostic methods}

The observed and expected agreements between STS method and combined method were 91.54 and 53.27\% of the observations, respectively for the identification of STHs infection. The respective observed and expected

Table 2 The sensitivity, specificity, NPV and PPV of FEC, KK, STS and APC techniques for the diagnosis of STHs against the gold standard among school children in ANRS, from October to December, 2019. $(n=520)$

\begin{tabular}{|c|c|c|c|c|c|c|c|c|}
\hline \multirow{3}{*}{ Method } & \multirow{3}{*}{ Species } & \multirow{3}{*}{ Result } & \multicolumn{6}{|c|}{ "Gold" standard } \\
\hline & & & Pos & $\mathrm{Neg}$ & Sensitivity & Specificity & NPV & PPV \\
\hline & & & & & $\%(95 \% \mathrm{Cl})$ & $\%(95 \% \mathrm{Cl})$ & $\%(95 \% \mathrm{Cl})$ & $\%(95 \% \mathrm{CI})$ \\
\hline \multirow[t]{8}{*}{ FEC } & $\mathrm{AL}$ & pos & 13 & 0 & $32.5(20.1-48.0)$ & $100(99.2-100)$ & 94.7 (92.4-96.3) & $100(77.2-100)$ \\
\hline & & Neg & 27 & 480 & & & & \\
\hline & $\mathrm{HW}$ & pos & 113 & 0 & $64.2(56.9-70.9)$ & 100 (98.9-100) & $84.5(80.7-87.7)$ & $100(96.7-100)$ \\
\hline & & Neg & 63 & 344 & & & & \\
\hline & $\pi$ & pos & 3 & 0 & 75.0 (31.0-95.4) & $100(99.3-100)$ & 99.8 (98.9-100) & $100(43.9-100)$ \\
\hline & & Neg & 1 & 516 & & & & \\
\hline & STHS & pos & 127 & 0 & $57.9(51.0-64.5)$ & $100(98.8-100)$ & $78.4(74.0--82.2)$ & $100(96.8-100)$ \\
\hline & & Neg & 85 & 308 & & & & \\
\hline \multirow[t]{8}{*}{ KK } & $A L$ & pos & 20 & 0 & $50.0(35.2-64.8)$ & $100(99.2-100)$ & $96.0(93.9-97.4)$ & $100(83.9-100)$ \\
\hline & & Neg & 20 & 480 & & & & \\
\hline & $\mathrm{HW}$ & pos & 98 & 0 & 55.7 (48.3-62.8 & 100 (98.9-100) & $81.5(77.5-84.9)$ & $100(96.2-100)$ \\
\hline & & Neg & 78 & 344 & & & & \\
\hline & $\Pi$ & pos & 3 & 0 & 75.0 (31.0-95.4) & $100(99.3-100)$ & 99.8 (98.9-100) & $100(43.9-100)$ \\
\hline & & Neg & 1 & 516 & & & & \\
\hline & STHS & pos & 117 & 0 & $55.2(48.5-61.7)$ & $100(98.8-100)$ & $76.4(72.0-80.3)$ & $100(96.8-100)$ \\
\hline & & Neg & 95 & 308 & & & & \\
\hline \multirow[t]{8}{*}{ STS } & $\mathrm{AL}$ & pos & 32 & 0 & $80.0(65.2-89.5)$ & $100(99.2-100)$ & $98.4(96.8-99.2)$ & $100(89.3-100)$ \\
\hline & & Neg & 8 & 480 & & & & \\
\hline & HW & pos & 137 & 0 & $77.8(71.1-83.3)$ & $100(98.9-100)$ & $89.8(86.4-92.5)$ & $100(97.3-100)$ \\
\hline & & Neg & 39 & 344 & & & & \\
\hline & $\pi$ & pos & 4 & 0 & $100(51.0-100)$ & $100(99.3-100)$ & $100(99.3-100)$ & $100(51.0-100)$ \\
\hline & & Neg & 0 & 516 & & & & \\
\hline & $\mathrm{STHS}$ & pos & 168 & 0 & $79.2(73.3-84.2)$ & $100(98.8-100)$ & 87.5 (83.6-90.6) & $100(97.8-100)$ \\
\hline & & Neg & 44 & 308 & & & & \\
\hline \multirow[t]{2}{*}{$\mathrm{APC}$} & HW & pos & 152 & 0 & $86.4(80.5-90.7)$ & 100 (98.9-100) & 93.5 (90.5-95.6) & $100(97.5-100)$ \\
\hline & & Neg & 24 & 344 & & & & \\
\hline
\end{tabular}


Table 3 The detection rate of FEC, KK and STS techniques individually and their combinations for the diagnosis of STHs parasites among school children in ANRS, from October to December, 2019. $(n=520)$

\begin{tabular}{|c|c|c|c|}
\hline \multirow[t]{2}{*}{ Methods } & \multirow{2}{*}{$\begin{array}{l}\text { Total } \\
\text { examined(N) }\end{array}$} & \multicolumn{2}{|l|}{ STHs } \\
\hline & & Pos (N (\%)) & $\%(95 \% \mathrm{Cl})$ \\
\hline FEC & 520 & $127(24.4)$ & $20.1-28.3$ \\
\hline KK & 520 & $117(22.5)$ & $19.1-26.3$ \\
\hline STS & 520 & $168(32.4)$ & $28.4-36.5$ \\
\hline $\mathrm{FEC}+\mathrm{KK}$ & 520 & $152(29.2)$ & $25.5-33.3$ \\
\hline $\mathrm{FEC}+\mathrm{STS}$ & 520 & $184(35.4)$ & $31.4-39.6$ \\
\hline $\mathrm{KK}+\mathrm{STS}$ & 520 & $186(35.8)$ & $31.8-40$ \\
\hline $\mathrm{FEC}+\mathrm{KK}+\mathrm{STS}$ & 520 & $195(37.5)$ & $33.4-41.7$ \\
\hline
\end{tabular}

Pos positive, Neg negative, $N$ number agreements 95.38 and $56.71 \%$ were obtained between APC method and combined method in the detection of hookworm infection (Table 4). The agreement of STS technique with the combined results was perfect in detecting STHs ( $\kappa=0.819)$ (Table 4). The KK method agreed perfectly in $T$. trichiura $(\kappa=0.856)$, substantially in A. lumbricoides $(\kappa=0.649)$ and hookworm $(\kappa=0.624)$ detections with combined techniques (Table 4). The FEC technique agreed perfectly in T. trichiura $(\kappa=0.856)$, substantially in hookworm $(\kappa=0.704)$, and moderately in A. lumbricoides $(\kappa=0.471)$ detections with gold standard (Table 4).

Furthermore, the $\kappa$ agreement between the APC and gold standard for the diagnosis of hookworm was perfect $(\kappa=0.893)$ (Table 4).

Table 4 Test agreement of FEC, KK, STS and APC techniques to detect STHs and S. mansoni against the gold standard among school children in ANRS, from October to December, 2019. $(n=520)$

\begin{tabular}{|c|c|c|c|c|c|c|c|c|}
\hline \multirow{3}{*}{ Methods } & \multicolumn{8}{|c|}{ Combined as a "Gold" standard } \\
\hline & \multirow[t]{2}{*}{ Species } & \multirow[t]{2}{*}{ Result } & \multirow{2}{*}{$\begin{array}{l}\text { Pos } \\
\text { (N) }\end{array}$} & \multirow{2}{*}{$\begin{array}{l}\mathrm{Neg} \\
\text { (N) }\end{array}$} & \multirow{2}{*}{$\begin{array}{l}\text { NOA } \\
\text { N (\%) }\end{array}$} & \multirow{2}{*}{$\begin{array}{l}\text { NAEC } \\
\text { N (\%) }\end{array}$} & \multirow{2}{*}{$\begin{array}{l}\text { Kappa-value; } \\
\text { ( } p \text {-value) }\end{array}$} & \multirow{2}{*}{$\begin{array}{l}95 \% \mathrm{Cl} \\
\text { of kappa }\end{array}$} \\
\hline & & & & & & & & \\
\hline \multirow[t]{8}{*}{ FEC } & AL & Pos & 13 & 0 & $493(94.81)$ & $469(90.19)$ & $0.471(0.001)$ & $0.306-0.636$ \\
\hline & & Neg & 27 & 480 & & & & \\
\hline & HW & Pos & 113 & 0 & $457(87.88)$ & $307(59.5)$ & $0.704(0.001)$ & $0.638-0.769$ \\
\hline & & Neg & 63 & 344 & & & & \\
\hline & $\Pi$ & Pos & 3 & 0 & $519(99.81)$ & $513(98.66)$ & $0.856(0.001)$ & $0.578-1.00$ \\
\hline & & Neg & 1 & 516 & & & & \\
\hline & STHs & Pos & 127 & 0 & $435(83.65)$ & $284.6(54.72)$ & $0.639(0.001)$ & $0.574-0.704$ \\
\hline & & Neg & 85 & 308 & & & & \\
\hline \multirow[t]{8}{*}{ KK } & $\mathrm{AL}$ & Pos & 20 & 0 & $500(96.15)$ & $463.1(89.05)$ & $0.649(0.001)$ & $0.507-0.790$ \\
\hline & & Neg & 20 & 480 & & & & \\
\hline & HW & Pos & 98 & 0 & $442(85.00)$ & $312.3(60.07)$ & $0.624(0.001)$ & $0.553-0.696$ \\
\hline & & Neg & 78 & 344 & & & & \\
\hline & $\pi$ & Pos & 3 & 0 & 519 (99.81) & $513(98.66)$ & $0.856(0.001)$ & $0.578-1.00$ \\
\hline & & Neg & 1 & 516 & & & & \\
\hline & STHs & Pos & 117 & 0 & $425(81.73)$ & $286.4(55.08)$ & $0.593(0.001)$ & $0.526-0.661$ \\
\hline & & Neg & 95 & 308 & & & & \\
\hline \multirow[t]{8}{*}{ STS } & $\mathrm{AL}$ & Pos & 32 & 0 & $512(98.46)$ & $452.9(87.10)$ & $0.881(0.001)$ & 0.799-0.962 \\
\hline & & Neg & 8 & 480 & & & & \\
\hline & HW & Pos & 137 & 0 & $481(92.50)$ & 299.7 (57.64) & $0.823(0.001)$ & $0.770-0.876)$ \\
\hline & & Neg & 39 & 344 & & & & \\
\hline & $\pi$ & Pos & 4 & 0 & $520(100)$ & $512(98.47)$ & $1.00(0.001)$ & $1.00-1.00$ \\
\hline & & Neg & 0 & 516 & & & & \\
\hline & STHs & Pos & 168 & 0 & 476 (91.54) & $277(53.27)$ & $0.819(0.001)$ & $0.769-0.869$ \\
\hline & & Neg & 44 & 308 & & & & \\
\hline \multirow[t]{2}{*}{ APC } & HW & Pos & 152 & 0 & $496(95.38)$ & $294.9(56.71)$ & $0.893(0.001)$ & $0.852-0.935$ \\
\hline & & Neg & 24 & 344 & & & & \\
\hline
\end{tabular}

Note: AL A. lumbricoides, HW Hookworm, $\pi$ T. trichiura, NOA Number of observed agreements, NAEC Number of agreements expected by chance, CI confidence interval 


\section{Discussion}

Accurate and sensitive diagnostic methods are necessary for the clinical and public health diagnosis of helminth infections, as well as for monitoring treatment and control interventions [21]. The rate of STHs in the present study was $40.8 \%$ which goes in line with previous findings in the Amhara region (36.4\%) [5]. The present study is also lower than the previous result recorded $52.4 \%$ in lake Hawassa [22], but this result is higher than the prevalence obtained 25.8\% in Peruvian Amazon [23]; $5.5 \%$ in Zimbabwe [24]; 6.73\% in Tanzania [25]; $16.2 \%$ in Kenya [26]; 14.5\% in Jawi [27] and 36.2\% in Bahir Dar [28]. These differences could be owing to differences in geographical, ecological, season of data collection and different diagnostics.

The STS technique is the simplest, fastest method to perform, requires less equipment and detects many species [9]. The detection rate of the STS method was 1.32, 2.48, and 1.33 times more sensitive than the FEC method to detect STHs, A. lumbricoides and T. trichiura, respectively. This result agrees with previous cross sectional study conducted in Peru [9]. The detection rate of STS method in the diagnosis of A. lumbricoides, hookworm and T. trichiura were also 1.63, 1.4 and 1.33 times more sensitive than KK method, respectively which is consistent with a study conducted in Peru by both methods [29].

In the present study, STHs were found in $24.4 \%$ of the students, using FEC technique and $22.5 \%$ by KK method. The difference in their diagnostic sensitivity is statistically significant $(P=0.001)$ which showed that FEC method was more sensitive than KK method. This result agrees with the study done in Ethiopia [30, 31], Co^ te d'Ivoire [32] and Tanzania [21]. However, the result of the present study is in contrast to previous studies done in Peusangan Bireuen [33] and Ethiopia [34, 35]. These differences in diagnostic performance might be due to stool sample size, number of slides prepared for diagnosis, interpersonal skill variations and technical errors of the two methods.

The detection rate of FEC method in the identification of hookworm infection was $21.7 \%$ which goes in line with findings from Bahir Dar City (20.6\%) [30] and rural Bahir Dar (23.7\%) [36]. The FEC method was 1.2 times more sensitive in hookworm detection than KK method in this study. Consistence results of FEC detection rate obtained 1.1 and 1.03 times more sensitive than KK method in Bahir Dar city and Gondar town respectively are reported previously [30, 34]. The possible justification might be due to hookworm egg disintegrated quickly due to glycerine if not observed within an hour [11, 37, 38], rapid degeneration of delicate hookworm eggs with time [16] and small amount of stool samples was processed in KK technique [29].
In the current study, the detection rate of APC method was $29.2 \%$ for the diagnosis of hookworm infection. Lower detection rate findings are recorded (13.6\%) in Colombia [39], (10.7\%) in Thailand [40] and (7.9\%) in Tanzania [41]. These differences in diagnostic performance might be due to areas endemicity, stool sample size, interpersonal skill variations and technical errors of the diagnostic method. The detection rate of APC method to hookworm infection was 1.55 times more sensitive than KK method. Similar findings were also reported in Colombia [39] and Tanzania [41]. The APC method (29.2\%) had also a higher detection rate than the FEC method (21.7\%) for the diagnosis of hookworm, as reported in other previous studies [32, 42]. The APC method was also more sensitive than the STS method for the diagnosis of hookworm infection as previously described by another author in Brazil [43].

In the present study, by taking the combined results as a "Gold" standard, the sensitivity of STS and KK techniques were 79.2 and $55.2 \%$, respectively in STHs detection. This result was quite different from previous study done in Peru reported that each KK and STS technique had $100 \%$ sensitivity for the detection of STHs [29]. The difference in diagnostic performance might be due to variations in interpersonal skill, small sample size and the "Gold" standard method used which is only a combination of KK and STS in the previous study. In the present study, the STS technique (79.2\%) was more sensitive than FEC technique (57.9\%) for the diagnosis of STHs infection. However, lack of previous similar studies made difficulty in making rigorous discussion on this finding.

In the present study, the FEC method and KK method had 57.9 and $55.2 \%$ sensitivity for STHs detection, respectively. The detection difference was statistically significant $(p=0.001)$. This result was consistent with similar studies done previously that showed that the FEC method has a lower sensitivity than KK method for the detection of STHs with the exception of hookworm infections [33-35]. However, the result of the present study is in contrary to the study done in $\mathrm{Co}^{\wedge}$ te d'Ivoire and Tanzania which showed that FEC method was more sensitive than KK method [21, 32]. These differences in diagnostic performance might be due to interpersonal skill variations and technical errors of the two methods. There might also be differences in gold standards and sample size used.

The sensitivity of APC method for hookworm detection was $86.4 \%$ which is comparable with previous study done in Colombia (76-92\%) [39]. This finding is also higher than previous study results (77.6\%) in Brazil [43], (45.2\%) in $\mathrm{Co}^{\wedge}$ te d'Ivoire [32] and (49\%) in Tanzania [41], but lower than previous finding (100\%) in Thailand [40]. The difference could be occurring due to inter 
personal variations, different "Gold" standards, technical errors and also quality of the media.

The agreement of STS technique with the combined results was perfect in detecting STHs species (A. lumbricoides $\kappa=0.881$, hookworm $\kappa=0.823$ and $T$. trichiura $\kappa=$ 1.00). There is no earlier data which have been conducted on the agreement of STS method with "Gold" standard method. But, the agreement result obtained in our study supports STS can be used as an alternative diagnostic method for STHs infections. This result also indicates that there is a need to make evaluation of the agreements of STS techniques rigorously with the "Gold" standard before using as a routine diagnostic method. The FEC technique agreed perfectly in $T$. trichiura $(\kappa=0.856)$, substantially in hookworm $(\kappa=0.704)$ and moderately in A. lumbricoides $(\kappa=0.471)$ detections with "Gold" standard. on the other hand, the agreement between the FEC method and single KK method was substantial for $A$. lumbricoides $(\kappa=0.62)$, moderate for T. trichiura $(\kappa=0.53)$ and fair for hookworm $(\kappa=0.34)$ in previous study done in Tanzania [21]. The difference could be arising due to the "Gold" standard method.

\section{Conclusions}

The present study revealed that STS method was more sensitive as compared to FEC and KK methods to detect STHs. Moreover, the APC method showed better performance for hookworm detection than the other three methods. Therefore, the employment of STS technique as a confirmatory test in routine laboratory and APC for research purposes will significantly aid in accurate diagnosis of parasitic infections in school children.

\section{Abbreviations \\ ANRS: Amhara National Regional State; APC: Agar plate culture; DALYs: Disability-adjusted life Years; FEC: Formal-ether concentration; KAP: Koga agar plate; KK: Kato Katz; MDA: Multi-drug administration; NPV: Negative predictive value; PPV: Positive predictive value; SSA: Sub- Saharan Africa; STHs: Soil transmitted helminths; STS: Spontaneous tube sedimentation; WHO: World Health Organization}

\section{Acknowledgements}

We would like to forward our gratitude to Bahir Dar University, College of Medicine and Health Sciences, School of Health Sciences, Department of Medical Laboratory Science for providing us the ethical clearance letter. Then we would like to acknowledge all the children, parents and school teachers who cooperated with us in this study. Finally, we would like to extend our deepest gratitude for the employed data collector for their innocent work and timely submitting the required data.

\section{Authors' contributions}

AF: Participated in the conception, design, data collection, analysis and interpretation. TH, MA, EN, AA and AM facilitated the data collection and management, drafted, analysis and critically reviewed the manuscript. All authors read and approved of the final manuscript.

\section{Authors' information}

AF is a lecturer at College of Medicine and Health Sciences, Debre Markos University in Medical Parasitology. TH is an associate professor at College of Medicine and Health Sciences, Bahir Dar University in Medical Parasitology. MA is an associate professor at College of Medicine and Health Sciences,
Bahir Dar University in Medical Parasitology. EN and AM are PhD at Bahir Dar University in department of Biology. AA is PhD at Institute of Health Carlos III, Madrid, Spain

\section{Funding}

Not applicable.

\section{Availability of data and materials}

The original data for this study is available from the corresponding author. Therefore, minimal data could be accessed upon request.

\section{Ethics approval and consent to participate}

Ethical clearance (protocol number $=0010 / 2019$ ) was obtained from College of Medicine and Health Science ethical review committee, Bahir Dar University and permission letter was obtained from ANRS health bureau. Written informed consent was secured from parents/guardians of each study participant and assent was also obtained from each child. Study participants infected with intestinal parasites were referred to doctors at the nearby health institution. Data were anonymized and confidentiality was maintained during all phases of the research activities.

\section{Consent for publication}

Not applicable.

\section{Competing interests}

The authors declare that they have no competing interests.

\section{Author details}

${ }^{1}$ Health Science College, Debremarkos University, P.o.box: 269, Debre Markos, Ethiopia. ${ }^{2}$ College of Medicine and Health Sciences, Bahir Dar University, P.O.Box: 79, Bahir Dar, Ethiopia. ${ }^{3}$ Science College, Bahir Dar University, P.O.Box: 79, Bahir Dar, Ethiopia. ${ }^{4}$ Mundo Sano Foundations, Institute of Health Carlos III, Madrid, Spain.

Received: 21 May 2020 Accepted: 21 October 2020

Published online: 29 October 2020

\section{References}

1. WHO. Human African Trypanosomiasis, Report of WHO Expert Comittee, WHO Technical Report. Geneva: World Health Organization; 2019.

2. Murray CJ, Vos T, Lozano R, Naghavi M, Flaxman AD, Michaud C, Ezzati M, Shibuya K, Salomon JA, Abdalla S. Disability-adjusted life years (DALYs) for 291 diseases and injuries in 21 regions, 1990-2010: a systematic analysis for the global burden of disease study 2010. Lancet. 2012;380(9859):2197-223.

3. Health FDRoEMo: Second edition of Ethiopia National Master Plan for Neglected Tropical Diseases. Addis Ababa, Ethiopia. 2016.

4. Negussu N, Mengistu B, Kebede B, Deribe K, Ejigu E, Tadesse G, Mekete K, Sileshi M. Ethiopia schistosomiasis and soil-transmitted helminthes control programme: progress and prospects. Ethiop Med J. 2017;55(Suppl 1):75.

5. Nute AW, Endeshaw $T$, Stewart AE, Sata E, Bayissasse B, Zerihun M, Gessesse D, Chernet A, Chanyalew M, Tedessse Z. Prevalence of soiltransmitted helminths and Schistosoma mansoni among a populationbased sample of school-age children in Amhara region, Ethiopia. Parasit Vectors. 2018;11(1):431.

6. WHO: Soil Transmitted Helminthiases School Age Children - National coverage Available from http://appswhoint/eases/ntddata/sth/sthhtm/ 2016.

7. Bethony J, Brooker S, Albonico M, Geiger SM, Loukas A, Diemert D, Hotez PJ. Soil-transmitted helminth infections: ascariasis, trichuriasis, and hookworm. Lancet. 2006:367(9521):1521-32

8. Terashima A, Marcos L, Maco V, Canales M, Samalvides F, Tello R. Spontaneous sedimentation in tube technique (SSTT) for diagnosis of intestinal parasites. Revista de gastroenterologia del Peru. 2009;29(4):305

9. Tello R, Terashima A, Marcos LA, Machicado J, Canales M, Gotuzzo E. Highly effective and inexpensive parasitological technique for diagnosis of intestinal parasites in developing countries: spontaneous sedimentation technique in tube. Int J Infect Dis. 2012:16(6):414.

10. Utzinger JBS, Knopp S, Blum J, Neumayr AL, Keiser J. Neglected tropical diseases: diagnosis, clinical management, treatment and control. Swiss Med Wkly. 2012;142(w13727):w13727.

11. WHO. Prevention and Control of Schistosomiasis and Soil-Transmitted Helminthiasis. World Health Organization. Tech Rep Series. 2002;912(1):57. 
12. WHO. Increasing Access to Diagnostics through Technology Transfer and Local Production. Geneva: World Health Organization; 2011

13. Habtamu K, Degarege A, Ye-Ebiyo Y, Erko B. Comparison of the Kato-Katz and FLOTAC techniques for the diagnosis of soil-transmitted helminth infections. Parasitol Int. 2011;60(4):398-402.

14. Knopp S, Rinaldi L, Khamis IS, Stothard JR, Rollinson D, Maurelli MP. Steinmann P, Marti H, Cringoli G, Utzinger J. A single FLOTAC is more sensitive than triplicate Kato-Katz for the diagnosis of low-intensity soiltransmitted helminth infections. Trans R Soc Trop Med Hyg. 2009;103(4): 347-54.

15. Utzinger LRL, Lohourignon LK. FLOTAC: a new sensitive technique for the diagnosis of hookworm infections in humans. Trans R Soc Trop Med Hyg. 2008;102(84):90

16. Tarafder MR, Carabin H, Joseph L, Balolong JE, Olveda R, McGarvey S. T estimating the sensitivity and specificity of Kato-Katz stool examination technique for detection of hookworms, Ascaris lumbricoides and Trichuris trichiura infections in humans in the absence of a 'gold standard'. Int J Parasitol. 2010;40(399):404.

17. ANRSEFD: Amhara National Regional State economic and finance development office report. Available at: www.amharabofed.gov.et/ population_report.html. 2017.

18. Ritchie LS. An ether sedimentation technique for routine stool examinations. Bull U S Army Med Dept. 1948;8(4):326.

19. Blatt JM, Cantos GA. Evaluation of techniques for the diagnosis of Strongyloides stercoralis in human immunodeficiency virus (HIV) positive and HIV negative individuals in the city of Itajai, Brazil. Brazil J Infect Dis. 2003;7(6):402-8.

20. Landis JR, Koch GG. An application of hierarchical kappa-type statistics in the assessment of majority agreement among multiple observers. Biometrics. 1977:363-74.

21. Speich B, Utzinger J, Marti H, Ame S, Ali S, Albonico M, Keiser J. Comparison of the Kato-Katz method and ether-concentration technique for the diagnosis of soil-transmitted helminth infections in the framework of a randomised controlled trial. Eur J Clin Microbiol Infect Dis. 2014;33(5):815-22.

22. Tadege B, Shimelis T. Infections with Schistosoma mansoni and geohelminths among school children dwelling along the shore of the Lake Hawassa, southern Ethiopia. PloS One. 2017:12(7):e0181547.

23. Errea RA, Vasquez-Rios G, Calderon ML, Siu D, Duque KR, Juarez LH, Gallegos $\mathrm{R}$, Uriol C, Rondon CR, Baca KP. Soil-transmitted helminthiasis in children from a rural community taking part in a periodic deworming program in the Peruvian Amazon. Am J Trop Med Hygiene. 2019;101(3):636-40.

24. Midzi N, Mduluza T, Chimbari MJ, Tshuma C, Charimari L, Mhlanga G, Manangazira P, Munyati SM, Phiri I, Mutambu SL. Distribution of schistosomiasis and soil transmitted helminthiasis in Zimbabwe: towards a national plan of action for control and elimination. PLoS Negl Trop Dis. 2014:8(8):e3014.

25. Mugono M, Konje E, Kuhn S, Mpogoro FJ, Morona D, Mazigo HD. Intestinal schistosomiasis and geohelminths of Ukara Island, North-Western Tanzania: prevalence, intensity of infection and associated risk factors among school children. Parasit Vectors. 2014;7(1):612

26. Odiere MR, Opisa S, Odhiambo G, Jura WG, Ayisi JM, KARANJA DM, Mwinzi PN. Geographical distribution of schistosomiasis and soil-transmitted helminths among school children in informal settlements in Kisumu City, Western Kenya. Parasitology. 2011;138(12):1569-77.

27. Sitotaw B, Mekuriaw H, Damtie D. Prevalence of intestinal parasitic infections and associated risk factors among Jawi primary school children, Jawi town, north-West Ethiopia. BMC Infect Dis. 2019;19(1):341.

28. Hailegebriel T. Prevalence of intestinal parasitic infections and associated risk factors among students at Dona Berber primary school, Bahir Dar, Ethiopia. BMC Infect Dis. 2017;17(1):362.

29. Machicado JD, Marcos LA, Tello R, Canales M, Terashima A, Gotuzzo E. Diagnosis of soil-transmitted helminthiasis in an Amazonic community of Peru using multiple diagnostic techniques. Trans R Soc Trop Med Hyg. 2012; 106(6):333-9.

30. Hailu T, Abera B. Performance evaluation of direct saline stool microscopy, Formol ether concentration and Kato Katz diagnostic methods for intestinal parasitosis in the absence of gold standard methods. Trop Dr. 2015;45(3): 178-82.

31. Taye S. Comparison of Kato-Katz and Formol-ether concentration methods for the diagnosis of intestinal helminthic infections among school children of Wonji Shoa town, eastern Ethiopia: a school based cross-sectional study. Am J Health. 2014;2:271-4.

32. Glinz D, Silué KD, Knopp S, Lohourignon LK, Yao KP, Steinmann P, Rinaldi L, Cringoli G, N'Goran EK, Utzinger J. Comparing diagnostic accuracy of KatoKatz, Koga agar plate, ether-concentration, and FLOTAC for Schistosoma mansoni and soil-transmitted helminths. PLoS Negl Trop Dis. 2010;4(7):e754.

33. Fitriani C, Panggabean M, Pasaribu A. The accuracy of formol-ether concentration in diagnosing soiltransmitted helminths in elementary school 27 Peusangan in Bireuen. In: IOP Conference Series: Earth and Environmental Science: 2018: IOP Publishing; 2018. p. 012040

34. Endris $\mathbf{M}$, Tekeste Z, Lemma W, Kassu A. Comparison of the Kato-Katz, wet mount, and formol-ether concentration diagnostic techniques for intestinal helminth infections in Ethiopia. ISRN Parasitol. 2012;2013.

35. Yimer M, Hailu T, Mulu W, Abera B. Evaluation performance of diagnostic methods of intestinal parasitosis in school age children in Ethiopia. BMC research notes. 2015;8(1):820

36. Birtukan B. Performance evaluation of three laboratory diagnostic methods for intestinal parasitic infections at rural Bahir Dar, Northwest Ethiopia: A cross-sectional study. J Health Sci. 2019;9(1).

37. WHO. Bench Aids for the diagnosis of intestinal parasites (with corrections). Geneva: World Health Organization; 2012.

38. Dacombe R, Crampin A, Floyd S, Randall A, Ndhlovu R, Bickle Q, Fine P. Time delays between patient and laboratory selectively affect accuracy of helminth diagnosis. Trans R Soc Trop Med Hyg. 2007:101 (2):140-5.

39. Barreto RE, Narvaez J, Sepulveda NA, Velasquez FC, Diaz SC, López MC, Reyes $\mathrm{P}$, Moncada LI. Combination of five diagnostic tests to estimate the prevalence of hookworm infection among school-aged children from a rural area of Colombia. Acta Trop. 2017;173:160-70.

40. SEDIONOTO B, WASESSOMBAT S, PUNSAWAD C, ANAMNART W. Diagnosis and prevalence of hookworm and Strongyloides stercoralis infections among schoolchildren in rural southern Thailand. Walailak Procedia. 2019;2019(1): IC4IR 101-IC104IR. 101

41. Knopp S, Mgeni AF, Khamis IS, Steinmann P, Stothard JR, Rollinson D, Marti $\mathrm{H}$, Utzinger J. Diagnosis of soil-transmitted helminths in the era of preventive chemotherapy: effect of multiple stool sampling and use of different diagnostic techniques. PLoS Negl Trop Dis. 2008;2(11):e331.

42. Jongwutiwes S, Charoenkorn M, Sitthichareonchai P, Akaraborvorn P, Putaporntip C. Increased sensitivity of routine laboratory detection of Strongyloides stercoralis and hookworm by agar-plate culture. Trans R Soc Trop Med Hyg. 1999;93(4):398-400

43. Inês EJ, Souza JN, Santos RC, Souza ES, Santos FL, Silva ML, Silva MP, Teixeira MC, Soares NM. Efficacy of parasitological methods for the diagnosis of Strongyloides stercoralis and hookworm in faecal specimens. Acta Trop. 2011:120(3):206-10.

\section{Publisher's Note}

Springer Nature remains neutral with regard to jurisdictional claims in published maps and institutional affiliations.

\section{Ready to submit your research? Choose BMC and benefit from:}

- fast, convenient online submission

- thorough peer review by experienced researchers in your field

- rapid publication on acceptance

- support for research data, including large and complex data types

- gold Open Access which fosters wider collaboration and increased citations

- maximum visibility for your research: over $100 \mathrm{M}$ website views per year

At BMC, research is always in progress.

Learn more biomedcentral.com/submissions 